\title{
“Queue up, you stupid!”: communicating about technology problems. An exploratory study of warning messages posted on machines in public places
}

\section{Beatrice Arbulla and Massimiano Bucchi}

Abstract

Keywords

Introduction
Communication about technology has long been neglected within the field of science and technology communication. This visual exploratory study focuses on how users can communicate with and about technology in public places through warning signs posted on technological devices. Three broad categories of messages have been identified: bad design, malfunctioning and disciplining users. By analyzing examples within each category, we suggest that studying these communicative situations can be a key to understanding how users are engaged in continuous, elaborate and sometimes even conflicting framing of technological devices (e.g. with regard to their purpose, appropriate uses, shifting boundaries between functioning/malfunctioning); how such framing, in turn, can be used to readjust/realign social behavior and organizational routines.

Technology communication, users interaction with technology, visual analysis.
"Signs
Signs are lost
Signs disappeared
Turn invisible"

(Talking Heads, Blind, 1988)

Communication about technology has long been neglected within the field of science and technology communication. Despite the fact that widespread labels to indicate this field include technology (e.g. "public communication of science and technology"), the topic of communication about technology is very rarely addressed in both theoretical and empirical contributions.

This paper focuses on a rather specific aspect within this broad theme: namely, communication about technology problems in public places. 
Our daily life is increasingly characterized by continuous interaction with technological devices. Improper use, malfunctioning, breakdowns are quite common. In public places, however, such problems and situations often require warning signs and additional instructions to help users deal with technology. Communication about technology — beyond traditional instructions and routines of use - is thus needed.

Such issues have been investigated, particularly in the past two decades, from the point of view of psychological study of design. In an influential series of books, Donald Norman has highlighted numerous examples of design inadequately addressing users' needs and thus often provoking incorrect use or requiring further interpretative work by users; advocating, also on this basis, a shift towards more "user-centered design" [Norman, 2000, p. 188].

Another relevant approach to the theme is offered by Science and Technology Studies. According to Latour [1992, pp. 86-90], technologies reflect a process of 'delegation' of operations that would otherwise have to be performed by humans (opening a door, or serving a coffee) and at the same time shape human action by prescribing certain behaviors and profiles of users. Technologies such as magnetic cards requiring hotel guests to save energy or car bumpers forcing drivers to slow down their driving speed are not neutral devices, but incorporate moral expectations about proper user behavior in a certain social context.

Drawing upon the work of Akrich, Latour speaks of scripts played by humans and non-human actors and calls description the retrieval of the script from the situation, defining actors, their competences and responsibilities. Such scripts can be explicit, like an instruction manual, but in most of daily life situations they are taken for granted, at least as long as artefacts and their users behave according to expectations.

When this is not the case, explicit communication is needed to re-align the script. Thus, in the case described by Latour, the breakdown of an automatic door requires a sign to be posted that redefines expectations towards user ("The door is on strike, please shut the door") while at the same time reaffirming, by referring to the technology in anthropomorphic terms, the routine delegation process.

A recent and relevant contribution for our theme can be found in the writings by Denis and Pontille [2010; 2014] and their blog Scriptopolis. ${ }^{1}$ The authors analyse how the performative role played by Paris urban inscriptions in shaping and organizing space is made possible also by painstaking and continuous maintenance and repairing. The stability and "material properties of objects" such as subway signs or technological devices cannot be taken for granted and established once and for all as intrinsic properties, but require constant update and adjustment; material order, just as interaction order, "must also be cared for and repaired" [Denis and Pontille, 2014, p. 11]. ${ }^{2}$ Warning messages posted on technological devices can also be seen as part of this process.

\footnotetext{
${ }^{1}$ http://www.scriptopolis.fr/en/.

${ }^{2}$ On urban inscriptions see also Latour and Hermant [1998]. On repairing and maintenance, see for example Graham and Thrift [2007] and Jarzabowski and Pinch [2014]. On the widespread tendency to neglect maintenance, repair and remodeling while focusing preeminently on innovation processes, see Edgerton [1999] and Edgerton [2006].
} 
Communicating

about

technology

problems
In the following pages we present different examples of signs posted in public places to communicate problems related to the functioning or use of certain technologies.

The examples collected fall within three broad categories, depending on the situation and aims.

\section{Readjusting/Clarifying affordance.}

These postings are mostly associated with what Norman describes as affordance, i.e. (appropriate) uses suggested by the device's design itself. The typical example is a door handle that suggests to pull (rather than push) the door. Unclear design can suggest inappropriate behavior, e.g. perceived affordance suggesting to pull a handle that has to be pushed, or rotated. An additional warning might therefore need to be posted to explicitly clarify correct use.

\section{Malfunctioning.}

These warning messages, like in Latour's famous automatic door example, refer to devices temporarily out of order. While re-describing the situation, they might also serve different practical aims: apologize (and thereby try to protect the organization's image) in the face of the user, discourage users from persisting in operations that may further damage the device or produce other undesirable outcomes for the user itself (e.g. loss of money), or re-delegate to humans some activities that the machine would routinely perform (again, Latour's door example).

\section{Disciplining users.}

Devices can be clearly designed and normally operating, but still require further instructions to avoid users behaving in ways that are considered inappropriate. In these cases, messages invite users to change their behavior in order to comply with the rules, routines and expectations of the organization or community of users. This communicative strategy is similar to those analyzed by Woolgar in his study of "configuration of computer users". Messages like "Warranty void if the seal is broken" on a PC or "do not apply pressure on the top cover" "delimit the nature and extent of access to the [technological] text", like a copyright warning on an academic article, "they are trying to control the relationship between the reader and the text by specifying constraints upon how it can be used"; users "may only cross the boundary and access the text if they agree to use it in certain prescribed ways" [Woolgar, 1990, p. 83].

What follows is a brief sample of the examples observed in our study. 


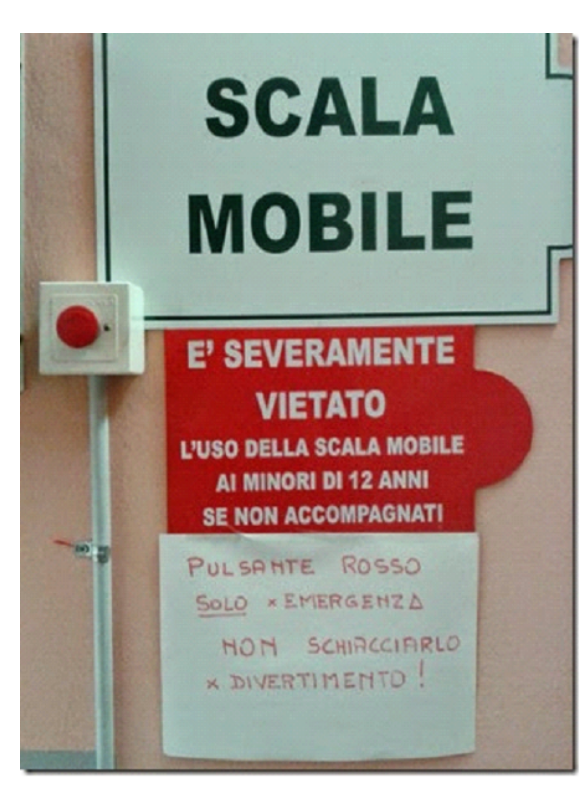

Figure 1. Warning sign under red button to stop mobile escalator at Politecnico di Torino. Reference: fulviocorno.blogspot.it, post published on $09 / 10 / 2014$
According to Donald Norman,

"[...] Complex things may require explanation, but simple things should not. When simple things need pictures, labels, or instructions, the design has failed" [Norman, 2000, p. 9].

The sign in Figure 1 refers to an emergency button to stop - in case of necessity - a mobile escalator. There are no relevant affordance and signifier references for the standard escalator user. How does the red button work? What is it there for? Here, the only perceived affordance is the red color which clearly attracts users' attention to the button. Apparently, a certain number of users just press the button, be it for curiosity or just because it's there in front of them - a button is there to be pushed after all!

Also, the plastic red sign that forbids the use of the escalator to unaccompanied children under 12 years of age further confuses users, because it is too close to the button. Therefore, individuals are encouraged to push it. The red (just a coincidence?) handwritten sign in capital letters, with a word underlined and with an

exclamation mark probably indicates that the member of the staff or the worker from the installation company who wrote it was annoyed and upset by repeated instances of users' misbehavior: "RED BUTTON ONLY FOR EMERGENCY. DO NOT PUSH IT JUST FOR FUN!". The short text is interesting because it "configures misuse" by identifying the motivation of users inappropriately pushing the button: they obviously do it just for fun! It thereby tries to exempt those installing the device or managing the premises from their own responsibility - it is not a question of misunderstanding due to poor or unclear communication on our side, the problem is childish users wanting to have fun. Besides, the sign does not actually clarify what the button is for, or when it exactly should be used, it just forbids users to 'have fun' with it, thereby also identifying behaviours and perhaps even categories of users (e.g. children) potentially disruptive to the technology as it is designed and put into place. 


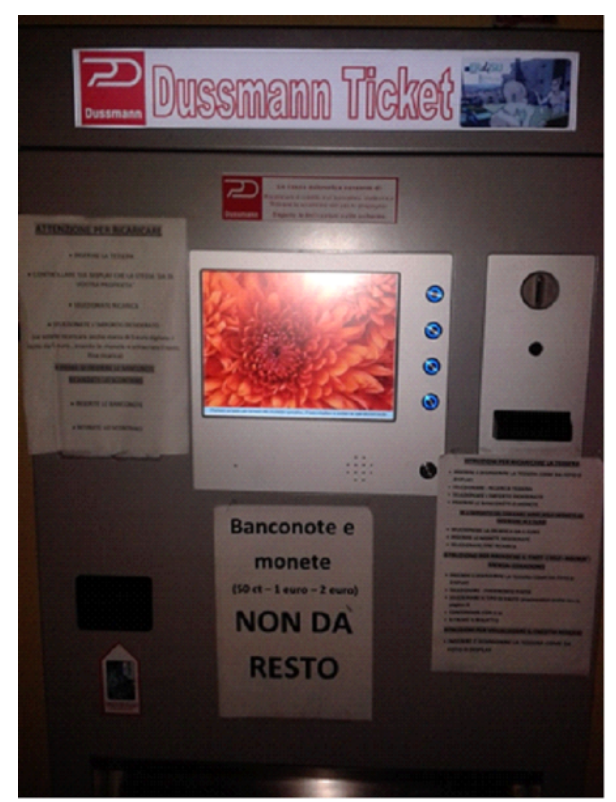

Figure 2. Newly installed machine to charge University Card, Food Hall of the University of Trieste, Piazzale Europa. Taken on 10/12/2014.
The device in Figure 2 operates in a University service center which includes a food catering service. The company in charge of the service has created a polygonal island in which there are several dishes. To pay for food, students and staff have to charge their cards through this machine. Then they can order, again through the machine, their food. As the several posted signs show, the instructions are quite complicated which results in great confusion particularly among new users - and endless queues, because students are supposed to know that they should first have a look at available menus, then go to the machine to order. Some may also discover only at the counter that their card does not have enough credit, and have to go back to the machine. Moreover, the large size of the screen suggests a touch screen function which is not actually the case. The user has to push the four blue buttons on the right side of the screen.

There is clearly a problem in the whole design of the space and in the positioning of the machine. Furthermore, the device does not provide appropriate affordance and signifiers and not even a proper mapping. As Norman says, "a natural mapping, by which I mean taking advantage of physical analogies and cultural standards, leads to immediate understanding" [Norman, 2000, p. 23]. The few commands available do not suggest spatial correspondence clearly. The banknotes slot is positioned at the bottom right of the device, and it is totally detached from other indicators and controls. Moreover, an advice was posted to indicate the correct insertion of university card, which suggests the correct input.

All of these elements contribute to create in the user a strong sense of confusion, which results in frequent expressions of frustration and of disappointment toward the whole system among students, teaching and administrative staff of the University.

\subsection{Malfunctioning}

The sign posted on this coffee maker in Figure 3 invites the customer to pay attention: "MACHINE OUT OF ORDER. THE COFFEE COMES CROOKED OUT OF THE CUP". The sign is written in capital letters on a red card. The presence of the date on which the sign was posted at the bottom right of the card communicates indirectly the temporary nature of the warning, hopefully to be removed when the coffee machine has been fixed. The malfunction sign might have been posted by a user, to prevent other users from inserting coins and selecting the product, wasting their money for spilled coffee. However, it could also have been posted by people working in the building, such as porters, to prevent complaints and requests for reimbursement that may eventually be addressed to them by visitors. However, 


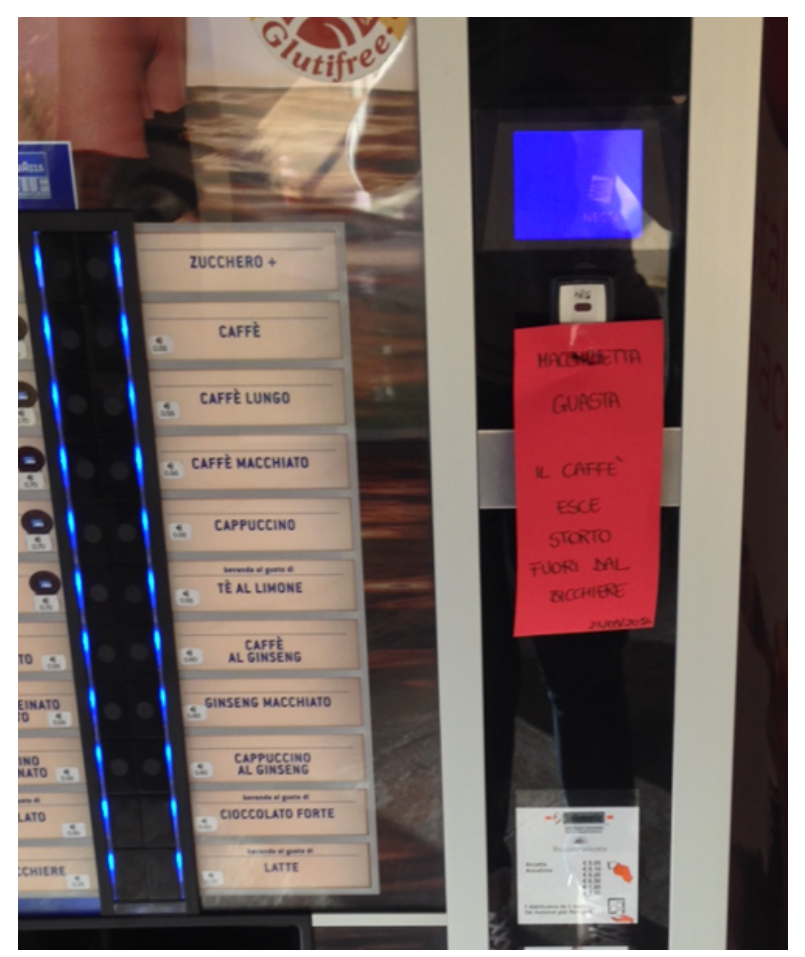

Figure 3. Coffee machine with a handwritten warning about malfunctioning, Local Health Service Unit, Trento. Taken 07/10/2014.

this is the only coffee machine in the building, and especially in cold seasons some users do not wish to go out for a coffee at the bar. So they insert their coins anyway, paying more attention and preparing themselves to twist the cup during the dripping of coffee. In a similar vein to Latour's "door-strike" example, thus, here humans have to actively compensate for the malfunctioning of the device.

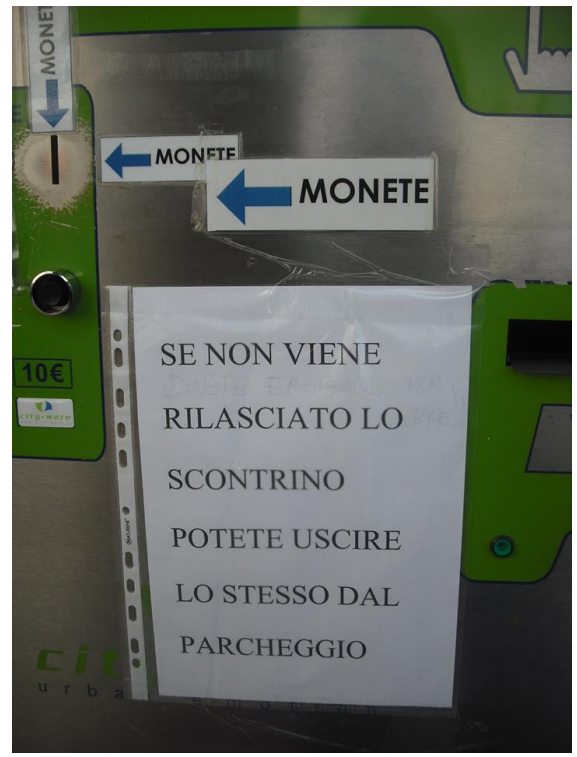

(a)

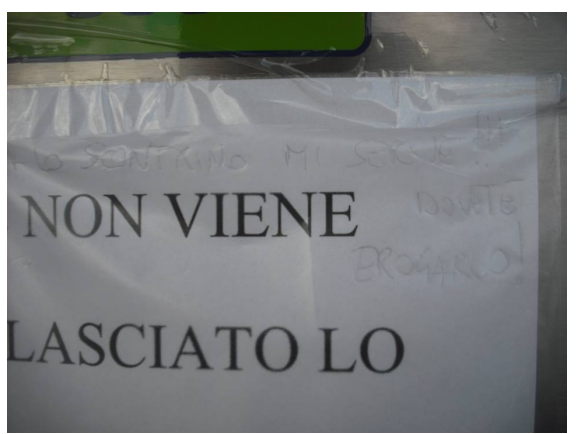

(b)

Figure 4. Parking ticket machine with a warning trying to reassure users about the functioning of the device (a) and with an handwritten complaint (b) at Cattinara Hospital, Trieste. Taken on 19/11/2014. 
This machine for paying for parking tickets does not always work properly.

Sometimes it does not issue the ticket receipt, which may worry some users that, being without the ticket, they may not be able to exit the parking gate. This results in confusion, frustration, queues and complaints with the staff. A warning message has thus been posted to reassure users that the larger device (i.e. the parking and its gates) will work despite the missing ticket and let the user who has paid out of the parking (Figure 4a): "IF THE RECEIPT IS NOT PRINTED YOU CAN

NEVERTHELESS EXIT PARKING". However, some users who probably need the receipt for fiscal or reimbursement react to this attempt to redefine "partial malfunctioning". So somebody wrote with a pen on the warning itself: "I NEED THE TICKET!!! YOU MUST SUPPLY IT" (Figure 4b). "Malfunctioning" is here defined differently by the company managing the parking and some users. The company tries to frame the parking as reasonably operating despite sometimes being unable to print receipts: gates open once the payment is made, after all. Thus they do not have to shut down the parking for a few days to repair it and avoid income losses. Before warning sign A was posted, most of the users would frame the parking as not properly operating and worry that they will be locked in with their cars. But even after reading warning sign A, however, some users are still not convinced: for them a "parking machine" which works properly should include a machine appropriately printing receipts for their use.

\subsection{Disciplining users}

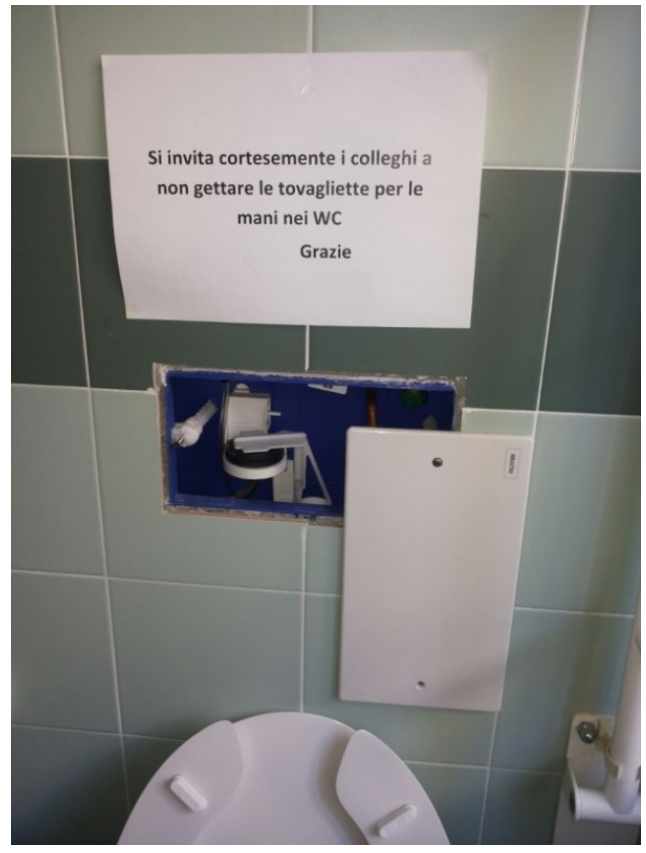

(a)

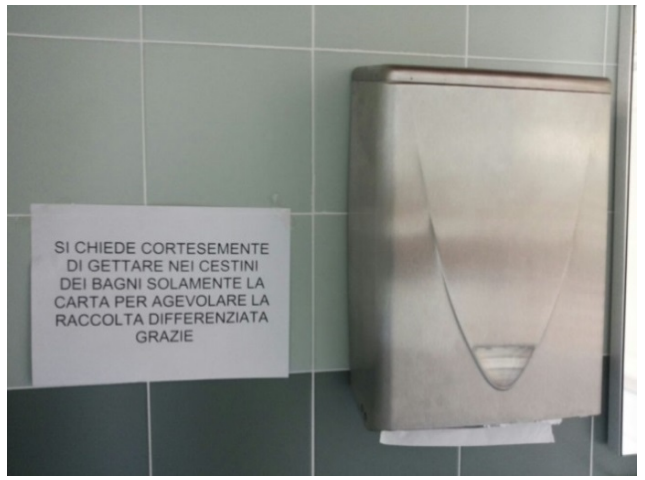

(b)

Figure 5. An office bathroom with signs recommending employees a proper use of the toilet (a) and of the waste bin (b), company office, Trieste. Taken on 23/10/2014.

Both signs shown in Figure 5 exhort the staff to properly use the office bathroom. The first one (Figure 5a) invites users not to throw hand towels down the toilet, because it could cause problems to the toilet flush or even obstruct it. These types of signs are quite common in office or public toilets, responding to users who are not so careful in disposing of their towels in the appropriate bin. However, users' 
inappropriate behavior may also be due to unclear positioning of waste bins or even to waste bins which are not emptied regularly, so that the toilet is perceived as the only or most obvious option.

The second warning sign (Figure $5 b$ ) invites users to comply with a different organizational need which in turn responds to environmental concerns. The sign recommends users to throw only paper in the waste bin, so that paper recycling is facilitated. Again, the sign suggests that users are at fault but users' behavior may also be triggered by the absence of waste bins for other materials inside or nearby the toilet. However, the organization has decided - or has been forced to, perhaps because the structure and dimension of spaces does not allow different practical arrangements - to focus on changing users' behavior. Here, proper technology use and proper social relations are defined at the same time. This may account for the very mild and gentle tone of both warnings, which ask colleagues courteously to comply with the suggested behavior, eventually thanking them for their understanding ("SI INVITA CORTESEMENTE", "SI CHIEDE CORTESEMENTE"). Notice that superficial reading of the two nearby warnings may result in perceived contradiction and potential confusion (Figure 5a recommends not to throw paper, Figure $5 \mathrm{~b}$ recommends to throw only paper, albeit with regard to different places, i.e. toilets and waste bins).

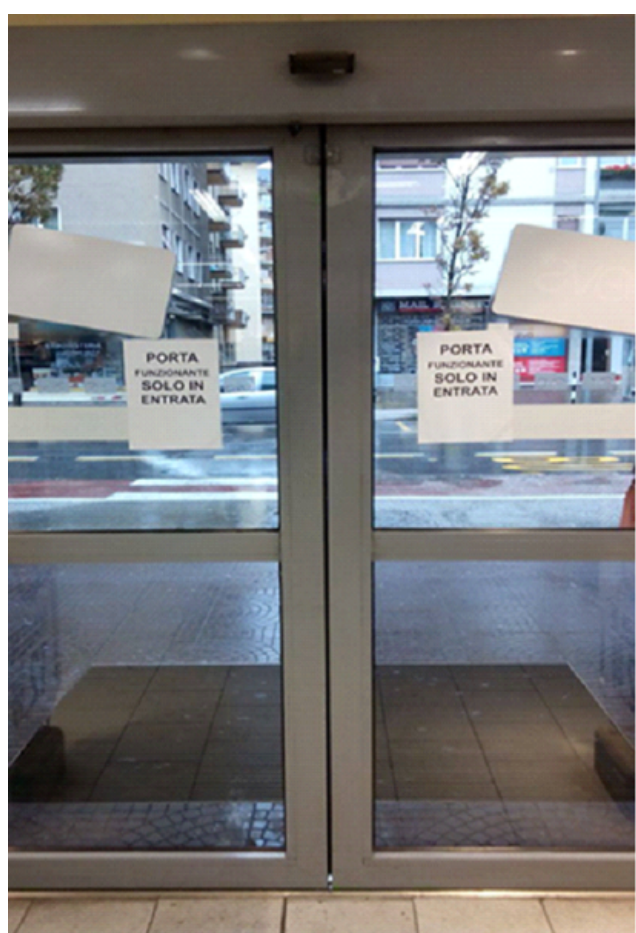

Figure 6. Automatic sliding doors in a clothes store, Trento 05/12/2014.
The sliding door in Figure 6 is not badly designed or malfunctioning. The sign posted, however, says "DOOR WORKING ONLY FOR ENTRANCE".

The point is, the sliding door works so well that it allows users to behave against the interest of the shop owners. If the customer activates the cell by passing nearby, the door opens and the customer can leave the shop easily after having had a quick look. However, the shop ownership and management prefers that the customer, once entered, walks all the way through the shop and has a chance to pass through the whole collection before going out. This marketing strategy is in some shops or even museums enforced by technology, with specially designed devices such as turnstiles, so that consumers or visitors have to go through a predesigned path from entrance to exit. This shop is not equipped with such technology: signs are posted to invite customers to comply with organizational and marketing needs.

The signs in Figure 7 have been posted in the same place of Figure 2. They should help users to understand the functioning of the new university food hall, which requires students and staff to charge their cards with money and then order food from the same machines. When these warnings appeared, the new system had been 


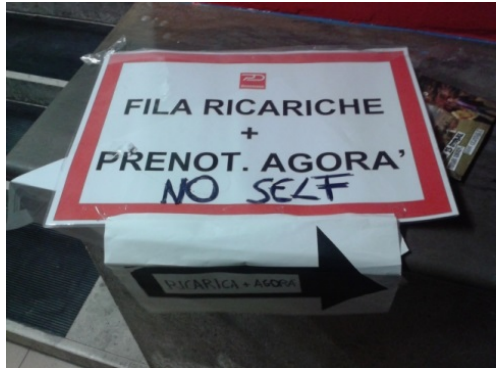

(a)

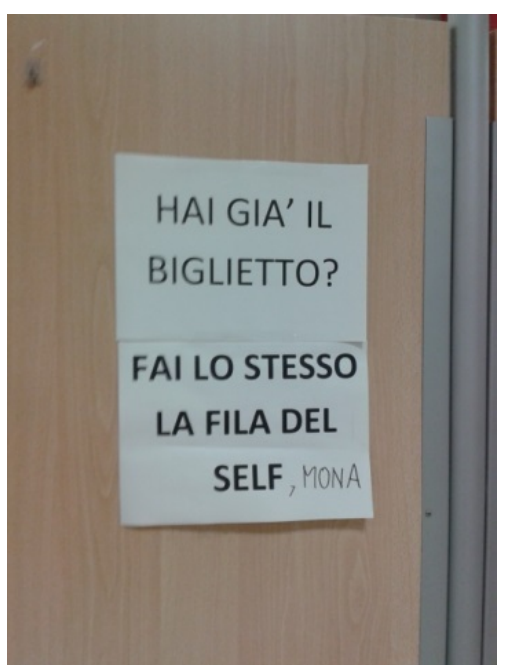

(b)

Figure 7. Signs that shows the correct use of the "Agorà dei giovani" system, at the dining hall of the University of Trieste, 10/12/2014.

in place for one year, but the managing company, in order to simplify the transition from the old to the new system, has kept also the old, standard "self service" systemin place, which allowed custmers to pay for food directly at the cashier. This coexistence of two different systems does not help the customers to understand and get used to - the new meal payment method.

Several frustrated and confused students line up in front of the device, asking other users for information about its correct use. So the staff has posted several warning signs.

Figure 7a tries to clarify that this is the "LINE FOR RECHARGING CARDS + BOOKING". The sign might have proved initially to be not so effective because another, handwritten warning has been added, presumably by a member of the staff: "NO SELF (service)".

Figure $7 \mathrm{~b}$ shows a warning composed of three elements. Two have been posted by the staff, perhaps on different occasions (the typehead differs slightly): "DO YOU ALREADY HAVE THE TICKET? YOU SHOULD NEVERTHELESS QUEUE UP”. A user has added an handwritten comma and jargon word to the last sentence, which now reads as "YOU SHOULD QUEUE UP, STUPID". This user probably intended to mock both the confusing organisation of the food hall and the continuous - and apparently, unsuccessful attempts - to have users understand and adapt to the new system while simultaneously accounting for the survival of the old system. In this case, the attempt to discipline users through warning signs has resulted in some users reacting by using the same strategy: e.g. adding to the signs comments of their own that further highlight the organisational problems by ridiculing and thereby delegitimising staff communication. 
Concluding

remarks: a never

ending,

continuous, conflictual and

largely

improvised

Script?
It is not the aim of this paper to try to draw general conclusions based on the brief exploration of examples of warning signs posted on machines in public places. We rather tried to suggest, through the analysis of these examples, that these and similar communicative situations can offer fruitful opportunities to study communicative interactions with and about technology.

Warning signs make explicit interpretative frames that are normally implicit with regard to technological devices: what is the purpose of a certain red button, what is the appropriate use of a card recharging machine or of a sliding door, when is a coffee machine or a parking lot actually out of order?

This communicative process is virtually never ending. In several of our examples not only are standard operating instructions by producers/installers insufficient and require additional postings; warning signs often add one to another but new users can come and new creative (mis)uses be put in place; potential defects and malfunctioning may emerge; users targeted by warning signs can misunderstand or simply resist signs and the framing they try to suggest or impose.

It is also not a discrete process, but rather a continuous communicative process where the definition of what is an appropriate use or a properly functioning machine can shift through interaction. In some of the examined examples, signs are part of boundary work about devices and their meaning. ${ }^{3}$ Is a parking lot which does not issue receipt tickets an "out of order" parking lot? Or is the user desperately claiming a receipt just a peculiar case of an annoying user who can be ignored or displaced by appropriate signs? Is a coffee machine spilling coffee out of order? Or can it still satisfyingly operate with a little help and goodwill from users who learn how to twist the coffee cup to minimise spillage? Is a sliding door just an entrance or also an exit for not so committed customers? Is this a waste bin or just a tool for recycling paper?

It is also a potentially conflictual process, an aspect perhaps slightly underrated by previous literature. Additional messages, handwritten comments and jokes testify to recalcitrant users who try to resist a certain definition of the situation, the device, and themselves: "This is a parking lot and I want my receipt"; "Queue up, you stupid!".

Borrowing again on the Latour/Akrich script metaphor, one could add that the script is never finished; actually it resembles more a canovaccio della commedia dell'arte, i.e. a script that is continuously rearranged - and often, largely improvised ${ }^{4}$ — by human and non-human players depending on the situation and purposes.

\footnotetext{
${ }^{3}$ For a general introduction to Boundary work in STS, see the classical work by Gieryin [1983]. In the context of technology use, see Woolgar [1990] and Grint and Woolgar [1997].

${ }^{4}$ In an original series of contributions, Davide Sparti has studied how the notion of improvisation, normally employed in context such as jazz music, can be fruitfully employed also in other everyday life contexts Sparti [2005; 2014].
} 
Akrich, M. (1992). 'The de-scription of technical objects'. In: Shaping Technology/Building society. Studies in Sociotechnical Change. Ed. by W. E. Bijker and J. Law. Cambridge, U.S.A.: The MIT Press.

Denis, J. and Pontille, D. (2010). Petite sociologie de la signalétique. Les coulisses des panneaux du métro. Paris, France: Les Presses des Mines.

- (2014). 'Maintenance work and the performativity of urban inscriptions: the case of Paris subway signs'. Environment and Planning D: Society and Space 32 (3), pp. 404-416. DOI: 10.1068/d13007p.

Edgerton, D. (1999). 'From innovation to use: Ten electic theses on the historiography of technology'. History and Technology 11 (2), pp. 37-41.

- (2006). The Shock of the Old. Technology and global history since 1900. London, U.K.: Profile.

Gieryin, T. (1983). 'Boundary-work and the demarcation of science from non-science: Strains and interests in professional ideologies of scientists'. American Sociological Review 48 (6), pp. 781-795.

Graham, S. and Thrift, N. (2007). 'Out of Order: Understanding Repair and Maintenance'. Theory, Culture E Society 24 (3), pp. 1-25.

Grint, K. and Woolgar, S. (1997). The Machine at Work. Technology, Work and Organization. Cambridge, U.K.: Polity Press.

Jarzabowski, P. and Pinch, T. (2014). 'Sociomateriality is 'the New Black': accomplishing repurposing, reinscripting and repairing in context'. M@n@gement 16 (5), pp. 579-592.

Latour, B. (1992). 'Where are the Missing Masses? Sociology of a Few Mundane Artefacts'. In: Shaping Technology/ Building Society: Studies in Sociotechnical Change. Ed. by W. Bijker and J. Law. Cambridge, U.S.A.: MIT Press.

- (2000). 'Mixing Humans and Nonhumans Together: The Sociology of a Door-Closer'. Social Problems 35, pp. 298-310.

Latour, B. and Hermant, É. (1998). Paris ville invisible. Les empêcheurs de penser enrond. Paris, France: La Découverte. URL: http://www . brunolatour.fr/sites/default/files/downloads/viii_paris-city-gb.pdf (visited on 2nd May 2015).

Norman, D. (2000). The design of everyday things. First ed. 1988. Cambridge, U.S.A.: MIT Press.

Sparti, D. (2005). Suoni inauditi. L'improvvisazione nel jazz e nella vita quotidiana. Bologna, Italy: Il Mulino.

- (2014). ‘On the Edge: A Frame of Analysis for Improvisation'. In: The Oxford Handbook of Critical Improvisation Studies. Ed. by G. Lewis and B. Piekut. Vol. 1. Oxford, U.K.: Oxford University Press.

Woolgar, S. (1990). 'Configuring the user. The case of usability trials'. The Sociological Review 38 (S1), pp. 58-99. DOI: 10.1111/j.1467-954X.1990.tb03349.x. Reprinted in Grint and Woolgar [1997].

Acknowledgments The authors wish to thank Francesca Musiani and Emma Weitkamp for their comments on earlier versions of this paper. 
Beatrice Arbulla, sociologist, collaborates to the research activities of the Science and Technology in Society Programme, Department of Sociology, University of Trento, Italy. E-mail: beatricearbulla@gmail.com.

Massimiano Bucchi is Professor of Science and Technology Communication at the University of Trento and has been visiting professor in several academic institutions in Asia, Europe and North America. He has published several books in Italy, Finland, China, Korea, Spain, Portugal, Latin America, U.K. and U.S.A. including Science in Society (Routledge, 2004), Beyond Technocracy (Springer, 2009), Handbook of Public Communication of Science and Technology (with B. Trench, Routledge, 2014) and papers in journals such as Nature and Science. He will become editor of the journal Public Understanding of Science (Sage) from 2016.

E-mail: massimiano.bucchi@unitn.it.

\section{How to cite}

Arbulla, B. and Bucchi, M. (2015). "“Queue up, you stupid!”: communicating about technology problems. An exploratory study of warning messages posted on machines in public places'. JCOM 14 (03), Y02. 